\title{
The search for excellence in Brazilian Nursing knowledge dissemination
}

\author{
Maria Lúcia Zanetti
}

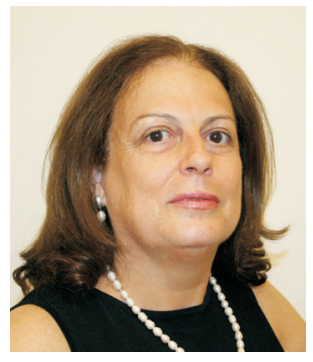

Nursing is a knowledge area whose representations are occupying different spaces in Brazilian and international institutions. These representations are based on the advancement of the profession in terms of the quality of its scientific production, excellence in human resource training and defense of the population's human rights. Research development, especially in recent decades, highlights Nursing, as illustrated by the excellence of its graduate programs, projects funded by support agencies, the quality of its research products and results, besides representations in Brazilian and international entities, among others.

New challenges have been included in the Nursing agenda though. The analysis of knowledge production shows that existing studies, in line with scientific development stages, are predominantly descriptive, which allowed researchers to get to know phenomena of interest to the profession. The growth of Brazilian graduate programs and advances achieved in terms of knowledge production have also made Nursing researchers explore other factors related to the phenomena nurses research on.

Current trends in Nursing research are increasingly oriented towards the explanation, forecasting and control phases of phenomena, seeking strong scientific evidence to support care actions. These challenges can partially explain the difficulties researchers are facing to have their manuscripts accepted in high-impact journals. Bottlenecks include problems related to sample representativeness, instruments validated for the culture of the country of origin, mastery of the language the manuscript will be published in, among others. On the other hand, themes of national or regional interest, of high social relevance, are accepted in Brazilian journals only. Thus, Brazilian researchers are facing difficulties to disseminate knowledge through publication in high-impact journals.

In that sense, the expand research excellence in Brazilian Nursing, investments are needed in internationalization as one route for researchers' complementary education at foreign colleges, in the increased qualified demand for projects submitted to funding agencies to get resources for research development, in the insertion of undergraduate Nursing students into scientific initiation programs, so as to identify potential talent for academic work, in permanent research training through collaborative work with researchers from other Brazilian researchers and abroad, and in graduate programs that offer the tools needed for scientific and technological knowledge development, significantly contributing to the country's development ${ }^{(1-2)}$. 


\section{References}

1. Mendes IAC, Trevizan MA. Ações do Centro Colaborador da OMS para o desenvolvimento da pesquisa em Enfermagem: o caso brasileiro. Acta Paul Enfermagem 2000; 13(2):9-15.

2. Marziale MHP. A transnacionalização regional da Enfermagem da America Latina. Rev. Latino-Am. Enfermagem 2009; 17(1):3-4.

Maria Lúcia Zanetti is member of the Editorial Board of the Latin American Journal of Nursing, and Associate Professor of the University of São Paulo at Ribeirão Preto College of Nursing, WHO Collaborating Centre for Nursing Research Development, Brazil, e-mail: zanetti@eerp.usp.br. 